\title{
Contribution of KRAS mutations and c.2369C $>T$ (p.T790M) EGFR to acquired resistance to EGFR-TKIs in EGFR mutant NSCLC: a study on circulating tumor DNA
}

Marzia Del Re ${ }^{1}$, Marcello Tiseo², Paola Bordi², Armida D'Incecco ${ }^{3}$, Andrea Camerini ${ }^{4}$, Iacopo Petrini ${ }^{5}$, Maurizio Lucchesi ${ }^{6}$, Alessandro Inno, Daniele Spada ${ }^{7}$, Enrico Vasile ${ }^{6}$, Valentina Citi $^{1}$, Giorgio Malpeli ${ }^{9}$, Enrica Testa ${ }^{8}$, Stefania Gori ${ }^{7}$, Alfredo Falcone $^{6}$, Domenico Amoroso ${ }^{4}$, Antonio Chella ${ }^{10}$, Federico Cappuzzo ${ }^{3}$, Andrea Ardizzoni ${ }^{2}$, Aldo Scarpa ${ }^{9}$, Romano Danesi ${ }^{1}$

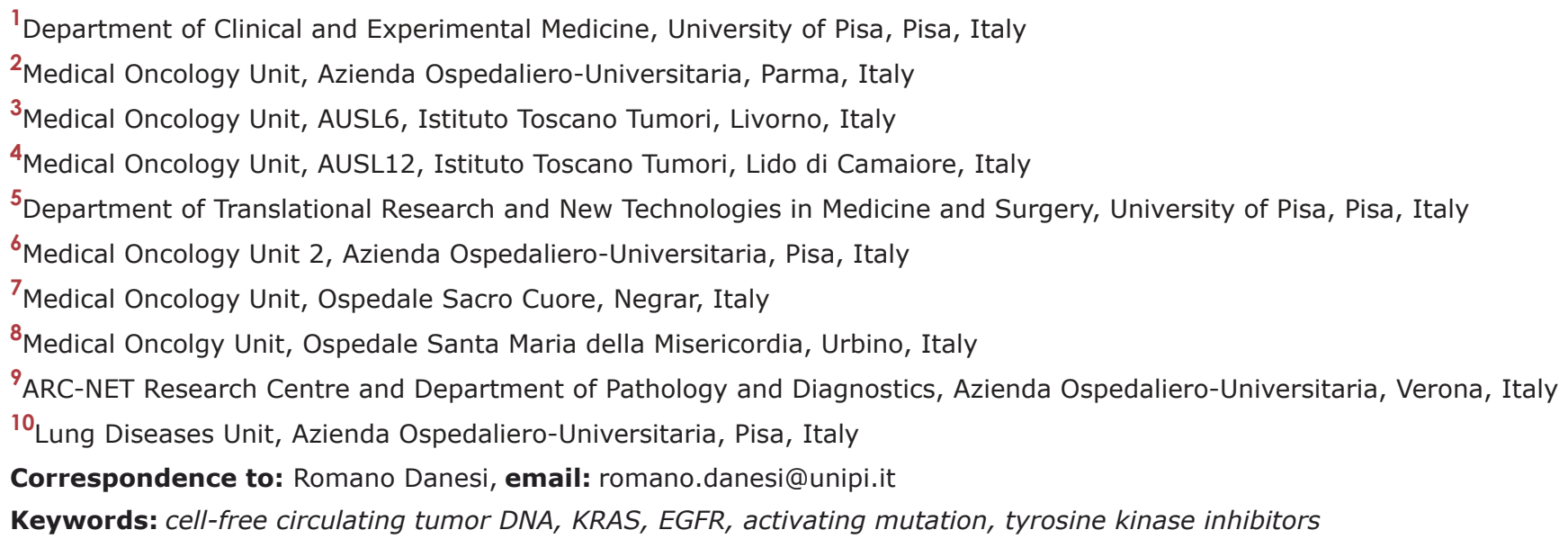

Published: January 20, 2016

\section{ABSTRACT}

Introduction: KRAS oncogene mutations (MUTKRAS) drive resistance to EGFR inhibition by providing alternative signaling as demonstrated in colo-rectal cancer. In non-small cell lung cancer (NSCLC), the efficacy of treatment with EGFR tyrosine kinase inhibitors (EGFR-TKIs) depends on activating EGFR mutations ( ${ }^{\mathrm{MUT}} E G F R$ ). However, inhibition of EGFR may select resistant cells displaying alternative signaling, i.e., KRAS, or restoration of EGFR activity due to additional ${ }^{\mathrm{MUT}} E G F R$, i.e., the c.2369C $>T$ (p.T790MEGFR).

Aim: The aim of this study was to investigate the appearance of ${ }^{\mathrm{MUT}}$ KRAS during EGFR-TKI treatment and their contribution to drug resistance.

Methods: This study used cell-free circulating tumor DNA (cftDNA) to evaluate the appearance of codon $12{ }^{\mathrm{MUT}}$ KRAS and ${ }^{\mathrm{P} \cdot T 790 \mathrm{M}}$ EGFR mutations in 33 advanced NSCLC patients progressing after an EGFR-TKI.

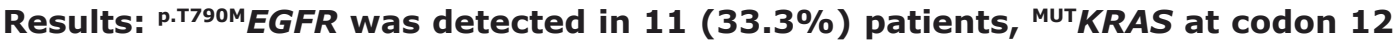
in $3(9.1 \%)$ while both ${ }^{\text {p.T790M EGFR and }{ }^{M U T} \text { KRAS codon } 12 \text { were found in } 13(39.4 \%)}$ patients. Six patients $(18.2 \%)$ were KRAS wild-type ( $\left.{ }^{\mathrm{WT}} K R A S\right)$ and negative for p.T790M EGFR. In 8 subjects paired tumor re-biopsy/plasma samples were available; the percent concordance of tissue/plasma was $62.5 \%$ for ${ }^{\text {p. }}$.7990 EGFR and $37.5 \%$ for ${ }^{M U T} K R A S$. The analysis of time to progression (TTP) and overall survival (OS) in ${ }^{{ }^{\top T}}$ KRAS vs. ${ }^{\text {MUT } K R A S}$ were not statistically different, even if there was a better survival with ${ }^{\text {wT } K R A S ~ v s .}{ }^{\text {MUT } K R A S, ~ i . e ., ~ T T P ~} 14.4$ vs. 11.4 months $(p=0.97)$ and $0 S 40.2$ vs. 35.0 months $(p=0.56)$, respectively. 


\section{Conclusions: ${ }^{M U T}$ KRAS could be an additional mechanism of escape from EGFR-TKI inhibition and cftDNA is a feasible approach to monitor the molecular development of drug resistance.}

\section{INTRODUCTION}

Activating mutations of epidermal growth factor receptor ( ${ }^{\mathrm{MUT}} E G F R$ ) predict sensitivity to tyrosine kinase inhibitors (TKI) in non-small cell lung cancer (NSCLC). Despite a very high response rate (about $70 \%$ ) to firstline treatment with the EGFR-TKIs (erlotinib, gefitinib or afatinib) in ${ }^{\mathrm{MUT}} E G F R$ NSCLC, tumors invariably progress after a median of 9-13 months from the beginning of treatment [1-3].

The understanding of the molecular basis of acquired resistance to TKI [4] and its application to treatment monitoring may improve treatment management by discontinuing ineffective treatments and directing towards most appropriate second line options before clinical progression may occur. Indeed, EGFR signaling is maintained in most cases that develop secondary resistance [5] suggesting that additional molecular mechanisms can bypass EGFR-TKI inhibition reactivating the signaling pathway. Several mechanisms of acquired resistance to EGFR-TKI have been described after progression, including c.2369C > T (p.T790M) EGFR gatekeeper mutation ( ${ }^{\text {p.T790M }} E G F R, ~-50 \%$ of patients) [6], MET (5-15\%) [7] or HER2 (12\%) [8] amplifications, PIK3CA (4.1\%) [9] or $B R A F(1 \%)$ [10] mutations or transformation into small cell histology (3\%) [11].

NSCLC heterogeneity can drive the therapeutic decisions [12]; therefore, tissue availability is increasingly recognized as a crucial issue. Unfortunately, the location of the tumor and the risk of complications are serious limitations to re-biopsies in NSCLC [13]. Alternatively, the detection of somatic mutations in cell-free tumor DNA (cftDNA) released in plasma could be instrumental for a better understanding of the genetic modifications driven by the selective pressure of drug treatments [14].

Interestingly, approximately $15-25 \%$ of patients with NSCLC have $K R A S$ mutations ( ${ }^{\mathrm{MUT}} K R A S$ ), resulting in constitutive activation of $K R A S$ signaling pathways. ${ }^{\mathrm{MUT}} K R A S$ is a negative predictor of benefit to anti-EGFR antibodies in colo-rectal cancer, while it seems to be a negative predictor of response to EGFR-TKIs in EGFR wild type $\left({ }^{\mathrm{WT}} E G F R\right)$ NSCLC patients [15]. In a previous study on a large collection of NSCLC tissues from patients with acquired resistance to EGFR-TKI, NRAS or KRAS mutations were not demonstrated [10]. Despite these negative results, we employed a sensitive ddPCR-based platform to investigate the presence of ${ }^{\mathrm{MUT}} K R A S$ alleles in plasma of patients resistant to EGFR-TKIs and we were able to demonstrate a potential role of ${ }^{\mathrm{MUT}} K R A S$ in acquired resistance to EGFR-TKI, besides the ${ }^{\mathrm{p} .7790 \mathrm{M}} E G F R$.
This finding reveals a potential new mechanism of resistance to EGFR-TKI and underscores the need of a periodic monitoring of somatic mutations of known oncogenes to deliver the best personalized treatment in a timely fashion.

\section{RESULTS}

The clinical characteristics of patients are reported in Table 1. Of 33 patients, $20(60.6 \%)$ were female and 13 $(39.4 \%)$ male. Median age was 62 years (range $41-75$ ); 32 patients were affected by a stage IV disease, while one was a stage IIIB NSCLC. The frequency of activating ${ }^{\mathrm{MUT}} E G F R$ was as follows: 20 patients $(60.6 \%)$ showed ex19del $E G F R, 10$ patients $(30.3 \%)^{\text {p.L858R }} E G F R, 2$ patients $(6.1 \%)^{\mathrm{p} . \mathrm{L} 747 \mathrm{p}} E G F R$ and 1 patient presented ${ }^{\mathrm{ex} 19 \mathrm{ins}} E G F R$ $(3 \%)$. As expected, the majority of them $(66.7 \%)$ was never-smokers, while 9 (27.2\%) and 2 (6.1\%) patients were former- and current-smokers, respectively. Twentyseven $(81.8 \%)$ subjects received gefitinib and $6(18.2 \%)$ erlotinib; the treatment was administered as first-line in $23(69.7 \%)$ (including 2 as maintenance), second-line in $6(18.2 \%)$ and third or further lines in 4 patients $(12.1 \%)$. The majority of them $(66.7 \%)$ presented partial response to TKI treatment and only 1 patient showed complete response (Table 1). Stable and progressive diseases were observed in $4(12.1 \%)$ and 6 subjects $(18.2 \%)$, respectively. Patients who have progressed on EGFR-TKI treatment, all receiving gefitinib, presented the following molecular profile in their primary tumors: ${ }^{\text {p.L747p }} E G F R$ and ${ }^{\text {ex } 19 \mathrm{del}} E G F R$ $\left(n=1\right.$ each) and ${ }^{\mathrm{p} . \mathrm{L858R}} E G F R(n=4)$. Median time to progression (TTP) was 13.6 months (95\% Confidence Interval, CI, range 8.0 - 19.2 months) and median overall survival (OS) was 40.2 months (95\% CI range 25.8-54.7 months) for the overall population.

The description of patients with activating ${ }^{\mathrm{MUT}} E G F R$ in their primary tumors as well as the percentages of ${ }^{\text {p. } .790 \mathrm{M}} E G F R$ and ${ }^{\mathrm{MUT}} K R A S$ alleles in cftDNA at the time of EGFR-TKI progression is reported in Table 2. In 16 patients $(48.5 \%)$, a codon $12{ }^{\mathrm{MUT}} K R A S$ was detected in cftDNA (Figure 1). In addition to this, the ${ }^{\mathrm{p} \cdot{ }^{.790 \mathrm{M}}} E G F R$ (c.2369C > T) second site mutation was present in the cftDNA of 24 patients (72.7\%). Interestingly, 13 patients $(39.4 \%)$ had both the ${ }^{\mathrm{MUT}} K R A S$ and ${ }^{\mathrm{p} . \mathrm{T} 790 \mathrm{M}} E G F R$, while 3 $(9.1 \%)$ and $11(33.3 \%)$ subjects displayed only ${ }^{\mathrm{MUT}} K R A S$ or ${ }^{\mathrm{p} . \mathrm{T} 790 \mathrm{M}} E G F R$, respectively (Figure 1). Six subjects displayed no mutations.

The association between smoking habit and the occurrence of ${ }^{\mathrm{MUT}} K R A S$ in cftDNA was investigated. Regarding the 11 patients with smoking history, $2(18.2 \%)$ 
Table 1: Characteristics of patients

\begin{tabular}{|c|c|c|}
\hline & & No. $(\%)$ \\
\hline \multicolumn{2}{|l|}{ Age years (range) } & $62(41-75)$ \\
\hline \multirow{2}{*}{ Gender } & male & $13(39.4 \%)$ \\
\hline & female & $20(60.6 \%)$ \\
\hline \multirow{3}{*}{ Smoking habit } & smokers & $2(6.1 \%)$ \\
\hline & never-smokers & $22(66.7 \%)$ \\
\hline & former-smokers & $9(27.2 \%)$ \\
\hline \multirow{2}{*}{ Stage } & IIIB & $1(3 \%)$ \\
\hline & IV & $32(97 \%)$ \\
\hline \multirow{4}{*}{ EGFR activating mutation } & ex19del & $20(60.6 \%)$ \\
\hline & p.L858R & $10(30.3 \%)$ \\
\hline & p.L747P & $2(6.1 \%)$ \\
\hline & ex19ins & $1(3 \%)$ \\
\hline \multirow[t]{3}{*}{ Line of treatment } & 1 & $23(69.7 \%)$ \\
\hline & 2 & $6(18.2 \%)$ \\
\hline & $\geq 3$ & $4(12.1 \%)$ \\
\hline \multirow[t]{2}{*}{ TKI } & gefitinib & $27(81.8 \%)$ \\
\hline & erlotinib & $6(18.2 \%)$ \\
\hline \multirow[t]{4}{*}{ Response } & $\mathrm{CR}$ & $1(3 \%)$ \\
\hline & PR & $22(66.7 \%)$ \\
\hline & $\mathrm{SD}$ & $4(12.1 \%)$ \\
\hline & PD & $6(18.2 \%)$ \\
\hline \multicolumn{2}{|l|}{ TTP months $(95 \% \mathrm{CI})$} & $13.6(8.0-19.2)$ \\
\hline \multicolumn{2}{|l|}{ OS months $(95 \% \mathrm{CI})$} & $40.2(25.8-54.7)$ \\
\hline
\end{tabular}

Abbreviations: TKI: tyrosine kinase inhibitor; TTP: time to progression; OS: overall survival

presented ${ }^{\mathrm{MUT}} K R A S$ and $9(81.8 \%)$ were wild-type $\left({ }^{\mathrm{WT}} K R A S\right)$. On the contrary, of 22 non-smoking subjects, $14(63.3 \%)$ were ${ }^{\mathrm{MUT}} K R A S$ and $8(36.4 \%){ }^{\mathrm{WT}} K R A S$. Fisher's extact test revealed that non-smoking habit and ${ }^{\mathrm{MUT}} K R A S$ were significantly associated $(p=0.026)$.

In 8 patients, paired re-biopsies and cftDNA were available. The 8 re-biopsies were performed in a different tumor site with respect to the initial diagnosis, the choice being dependent on several factors, i.e., anatomical accessibility, new or progressing lesions. The analysis of re-biopsies by standard methods and ddPCR demonstrated p. T790M EGFR in 4 (standard) vs. 2 (ddPCR) samples and ${ }^{\mathrm{MUT}} K R A S$ in none (standard) vs. 3 (ddPCR) specimens. p.T790M EGFR and ${ }^{\mathrm{MUT}} K R A S$ were detected in 7 and 5 cftDNA specimens, respectively.

The analysis of KRAS status by ddPCR in the biopsies at diagnosis revealed the presence of ${ }^{\mathrm{MUT}} K R A S$ in 2 patients, who were ${ }^{\mathrm{WT}} K R A S$ by standard method. Therefore, the percentage of patients developing ${ }^{\mathrm{MUT}} K R A S$ as a mechanism of acquired resistance is $42 \%$ (14 patients). In terms of TTP and OS, there was no difference between these patients and the others ( $p=0.19$ and $p=0.13$, respectively).

The concordance between tissue of re-biopsies (standard methods) and plasma (ddPCR), calculated by combining positive and negative results, was $62.5 \%$ and $37.5 \%$ for ${ }^{\text {p.T790M }} E G F R$ and ${ }^{\mathrm{MUT}} K R A S$, respectively (Table 3 ). Moreover, three paired samples found positive for the ${ }^{\text {p. } .7900 \mathrm{M}} E G F R$ on re-biopsies (standard methods) and on cftDNA (ddPCR), were negative by ddPCR on primary tissue (Table 3).

The analysis of survival data stratified according to $K R A S$ status in cftDNA, showed that TTP and OS were not statistically different, despite a trend towards a better survival in ${ }^{\mathrm{WT}} K R A S$ vs. ${ }^{\mathrm{MUT}} K R A S$ patients, i.e., TTP 14.4 vs. 11.4 months $(p=0.97)$ and OS 40.2 vs. 35.0 months $(p=0.56)$, respectively.

Finally, samples were analysed also for codons 13 (p.G13D) and $61{ }^{\mathrm{MUT}} K R A S$ and ${ }^{\mathrm{MUT}} N R A S$, and ${ }^{\mathrm{V}}{ }^{600 \mathrm{E}} B R A F$ and all the samples were found to be wild-type. Unfortunately, due to sample restriction, cftDNA was insufficient to perform the analysis of PI3K/Akt mutations. 
Table 2: Types of activating mutations of ${ }^{\mathrm{MUT}} E G F R$ in primary tumor and $\%$ of ${ }^{\mathrm{p} . \mathrm{T} 790 \mathrm{M}} E G F R$ and ${ }^{\mathrm{MUT}} \mathrm{KR} A S$ alleles in cftDNA. "__" Indicates wild-type allele

\begin{tabular}{|c|c|c|c|}
\hline Sample & Activating ${ }^{\mathrm{MUT}} E G F R$ & ${ }^{\mathrm{p} . \mathrm{T} 790 \mathrm{M}} E G F R \%$ & ${ }^{\mathrm{MUT}} \mathrm{KR} A S \%$ \\
\hline 1 & Ex19del & $7 \%$ & $2 \%$ \\
\hline 2 & p.L858R & $11 \%$ & - \\
\hline 3 & Ex19del & $1 \%$ & $1 \%$ \\
\hline 4 & Ex19del & $3 \%$ & $2 \%$ \\
\hline 5 & Ex19del & - & $1 \%$ \\
\hline 6 & Ex19del & - & $1.5 \%$ \\
\hline 7 & Ex19del & $1.5 \%$ & $1 \%$ \\
\hline 8 & p.L858R & $1 \%$ & - \\
\hline 9 & Ex19del & - & - \\
\hline 10 & Ex19del & - & - \\
\hline 11 & p.L858R & - & - \\
\hline 12 & p.L858R & $5 \%$ & - \\
\hline 13 & Ex19del & - & - \\
\hline 14 & p.L747P & $2 \%$ & - \\
\hline 15 & p.L858R & - & - \\
\hline 16 & Ex19del & $1 \%$ & - \\
\hline 17 & Ex19del & $1 \%$ & $2 \%$ \\
\hline 18 & Ex19del & $16 \%$ & $1 \%$ \\
\hline 19 & p.L858R & $23 \%$ & $1 \%$ \\
\hline 20 & Ex19del & $96 \%$ & $98 \%$ \\
\hline 21 & Ex19del & - & - \\
\hline 22 & Ex19ins & - & $1 \%$ \\
\hline 23 & Ex19del & $33 \%$ & $2 \%$ \\
\hline 24 & p.L747P & $1 \%$ & $1 \%$ \\
\hline 25 & p.L858R & $5 \%$ & $2 \%$ \\
\hline 26 & p.L858R & $3 \%$ & $1 \%$ \\
\hline 27 & Ex19del & $9 \%$ & $3 \%$ \\
\hline 28 & p.L858R & $14 \%$ & - \\
\hline 29 & Ex19del & $28 \%$ & - \\
\hline 30 & p.L858R & $7 \%$ & - \\
\hline 31 & Ex19del & $39 \%$ & - \\
\hline 32 & Ex19del & $6 \%$ & - \\
\hline 33 & Ex19del & $43 \%$ & - \\
\hline
\end{tabular}

\section{DISCUSSION}

The present study demonstrates the presence of ${ }^{\mathrm{MUT}} K R A S$ in the cftDNA of a significant proportion of patients progressing after EGFR-TKI treatment. In addition to this, the present study provides evidence that sensitizing ${ }^{\mathrm{MUT}} E G F R$ and ${ }^{\mathrm{MUT}} K R A S$ can coexist after the selective pressure of EGFR-TKI treatment.

p. $7790 \mathrm{M} E G F R$ determines acquired resistance by increasing the affinity of EGFR to ATP $[16,17]$. p. $.790 \mathrm{M} E G F R$ has been described in re-biopsies of $50-63 \%$ of tumors progressing under EGFR-TKI treatment $[4,11]$ and in the cftDNA at a frequency similar to our study [18-0]. Because drugs active on ${ }^{\mathrm{p} . \mathrm{T} 790 \mathrm{M}} E G F R$, such as AZD9291 and rociletinib [21, 22], are under clinical study and will be available soon in the clinical practice, the identification of this molecular marker is of utmost clinical relevance.

In our study, ${ }^{\text {p. }}{ }^{7790 \mathrm{M}} E G F R$ was more frequent in ${ }^{\text {L858R }} E G F R$ patients than in ${ }^{\text {ex19del }} E G F R$ ones ( $80 \%$ vs. $67 \%$ ); on the contrary, ${ }^{\mathrm{MUT}} K R A S$ in cftDNA was detected in $55 \%$ of patients with ${ }^{\text {ex } 19 d e l} E G F R$ vs. $30 \%$ of patients with 
${ }^{\text {L858R }} E G F R$. To our knowledge, a mechanism of resistance depending on activating ${ }^{\mathrm{MUT}} E G F R$ has not been previously reported; however, this cohort is too small to draw any conclusion.

${ }^{\text {MUT }} E G F R$ and ${ }^{\mathrm{MUT}} K R A S$ are mutually exclusive in primary NSCLC and only anecdotal case reports described their coexistence $[23,24] .{ }^{\text {MUT }} K R A S$ occurs in approximately $20 \%$ of NSCLC cases at diagnosis, more frequently in Caucasian population, adenocarcinomas, males and current smokers $[25,26]$. About $90 \%$ of $K R A S$ mutations occur in exon 2 (codon 12 and 13), while exon 3 (codon 61) is less frequently involved [26, 27]; in never-smokers with lung adenocarcinoma, ${ }^{\text {MUT }} K R A S$ is more frequently a transition ( $\mathrm{G}$ to $\mathrm{A}$ ) compared to transversion in current smokers [25]. Colo-rectal cancer cells with ${ }^{\mathrm{MUT}} K R A S$ treated with anti-EGFR monoclonal antibodies are able to escape growth inhibition by several mechanisms, including ${ }^{\mathrm{MUT}} R A S$ [28]. While the role of ${ }^{\mathrm{MUT}} K R A S$ in primary resistance to EGFR-TKIs in molecularly unselected NSCLC is quite well established $[29,30]$, its development and role in acquired resistance to EGFR-TKIs in ${ }^{\mathrm{MUT}} E G F R$ patients has not been explored in detail. In a previous work on a large collection of NSCLC tissues from patients with acquired EGFR-TKI resistance, ${ }^{\mathrm{MUT}} N R A S$ or ${ }^{\mathrm{MUT}} K R A S$ were not demonstrated [10]. However, comparison with the present results is not possible because detailed information were not provided neither on the timing of sampling with respect of development of TKI resistance nor on the type of tissue analysed. Therefore, we addressed this issue and a sensitive ddPCR-based platform was employed to investigate the presence of ${ }^{\mathrm{MUT}} K R A S$ alleles besides the well-known ${ }^{\mathrm{p} \cdot \mathrm{T} 790 \mathrm{M}} E G F R$. Due to its high sensitivity,
ddPCR is able to identify small amounts of ${ }^{\mathrm{MUT}} K R A S$ and many methodological issues need to be addressed prospectically, particularly the threshold level of both ${ }^{\mathrm{MUT}} K R A S$ and ${ }^{\mathrm{p} . \mathrm{T} 790 \mathrm{M}} E G F R$ to be considered clinically relevant. However, a mechanism of drug resistance does not necessarily reflect biologic aggressiveness and the lack of difference in OS between $K R A S$ wild-type and mutated patients it is therefore not surprising. The numeric dimension of the cell clone bearing ${ }^{\mathrm{MUT}} K R A S$ should be taken into consideration as well. Nevertheless, despite the low proportion of smokers in our cohort, the high prevalence of ${ }^{\mathrm{MUT}} K R A S$ could support its role of as mechanism of acquired resistance.

Eight patients underwent re-biopsy after tumor progression during EGFR-TKI, allowing a comparison between tissue and cftDNA. The detection of mutations in cftDNA but not in re-biopsy, using both standard methods and ddPCR, could suggest the presence of heterogeneity within metastatic sites or the lower performance of ddPCR in the presence of paraffin. Nevertheless, the detection of mutations in both plasma and tissue by ddPCR, but not by standard methods, could be due to the higher sensitivity of ddPCR analysis. Two patients, initially diagnosed ${ }^{\mathrm{WT}} K R A S$ by standard method, were re-analysed by ddPCR and were found ${ }^{\mathrm{MUT}} K R A S$ in the primary biopsy, suggesting that the ${ }^{\text {MUT }} K R A S$ clone co-existed with activating ${ }^{\text {MUT }} E G F R$ since the beginning, as also demonstrated in previous reports $[23,24]$. In these patients, ${ }^{\mathrm{MUT}} K R A S$ cannot strictly be considered a mechanisms of resistance but it could be possible that EGFR-TKI treatment may have favored the expansion of ${ }^{\mathrm{MUT}} K R A S$-positive clones. However, conclusions cannot be drawn as pre-treatment cftDNA was not available.

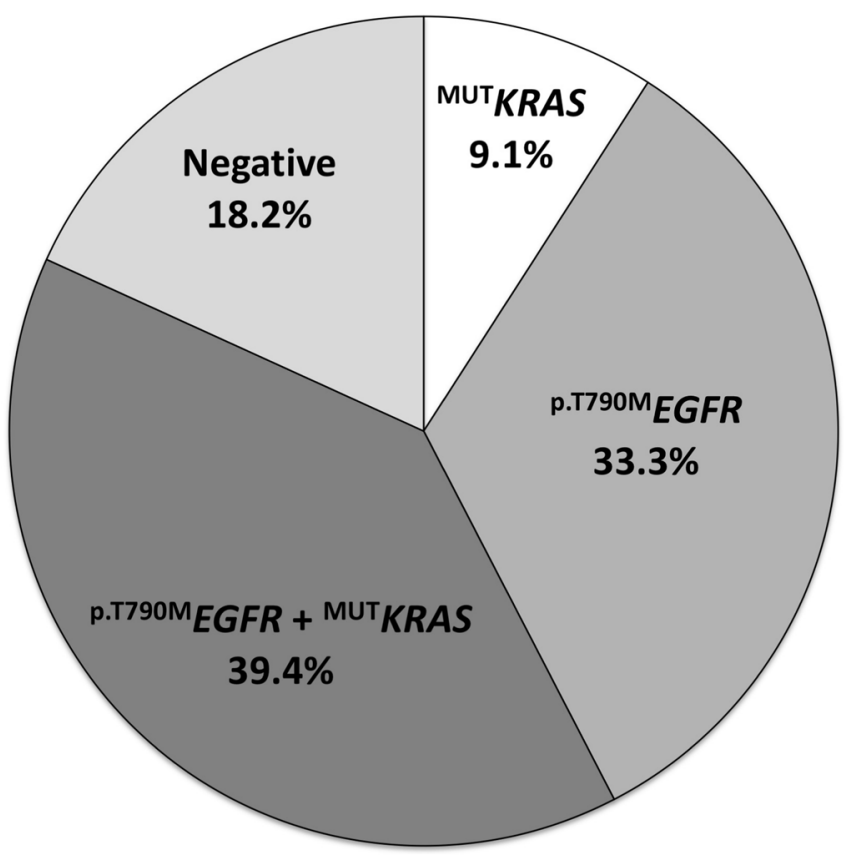

Figure 1: Occurrence of KRAS and p.T790M mutations in cftDNA of NSCLC patients treated with EGFR-TKI 
Table 3: Molecular analysis of re-biopsies and comparison with cftDNA

\begin{tabular}{|c|c|c|c|c|c|c|c|c|}
\hline \multirow[b]{2}{*}{ Patient n. } & \multicolumn{2}{|c|}{ Primary tumor } & \multicolumn{4}{|c|}{ Re-biopsy } & \multicolumn{2}{|c|}{ cftDNA } \\
\hline & $\begin{array}{c}{ }^{\mathrm{MUT}} K R A S \\
\text { std }\end{array}$ & $\begin{array}{c}{ }^{\mathrm{MUT}} K R A S \\
\text { ddPCR }\end{array}$ & $\begin{array}{c}\text { p.T790M } E G F R \\
\text { ddPCR }\end{array}$ & $\begin{array}{c}{ }^{\mathrm{MUT}} K R A S \\
\text { ddPCR }\end{array}$ & $\begin{array}{c}\text { p.T790M } E G F R \\
\text { std }\end{array}$ & $\begin{array}{l}{ }^{\mathrm{MUT}} K R A S \\
\text { std }\end{array}$ & $\begin{array}{c}\text { p.T790M } E G F R \\
\text { ddPCR }\end{array}$ & $\begin{array}{c}{ }^{\mathrm{MUT}} K R A S \\
\text { ddPCR }\end{array}$ \\
\hline 2 & - & NA & - & - & - & - & Mut & - \\
\hline 4 & - & Mut & Mut & Mut & - & - & Mut & Mut \\
\hline 5 & - & Mut & - & Mut & - & - & - & Mut \\
\hline 19 & - & - & - & - & Mut & - & Mut & Mut \\
\hline 20 & - & - & - & - & - & - & Mut & Mut \\
\hline 23 & - & - & Mut & Mut & Mut & - & Mut & Mut \\
\hline 28 & - & NA & - & - & Mut & - & Mut & - \\
\hline 30 & - & NA & - & - & Mut & - & Mut & - \\
\hline
\end{tabular}

Mut: presence; “_“": absence of mutation; NA: sample not available; std: standard sequencing approach.

Our observation is a pivotal evidence of the presence of ${ }^{\mathrm{MUT}} K R A S$ in cftDNA of tumors with sensitizing ${ }^{\text {MUT }} E G F R$ resistant to EGFR-TKIs. A small percentage of our patients received EGFR-TKI as third line therapy and a new biopsy was not repeated at this time. It could be possible that ${ }^{\mathrm{MUT}} K R A S$ appeared before the initiation of TKI as a mechanism of resistance to previuos therapy. This hypotesis is weakened by the evidence that patients given second or further lines of therapy showed TTP and OS similar to patients treated in first line, although a mechanism of resistance does not necessarily affect survival. The presence of ${ }^{\mathrm{MUT}} K R A S$ has been recently reported using next generation sequencing analysis of tumor re-biopsies after progression under EGFR-TKI treatment [31], similarly to colo-rectal cancer treated with EGFR antibodies $[32,33]$. It remains to be determined if the presence of ${ }^{\mathrm{p} . \mathrm{T} 790 \mathrm{M}} E G F R$ and ${ }^{\mathrm{MUT}} K R A S$ coexist in the same tumor cell or arise in different subclones.

Targeting ${ }^{\mathrm{MUT}} \mathrm{KRAS}$ proteins is still a challenge $[34,35]$. Theoretically, combined treatment with KRAS and EGFR inhibitors can be administered to patients

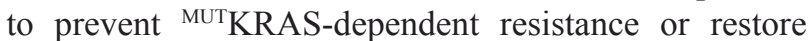
sensitivity to EGFR-TKIs, as recently demonstrated co-targeting EGFR and MEK [36]. To date, ${ }^{\text {p.T790M }} E G F R$ remains the most important predictor of efficacy of third generation EGFR-TKIs. Moreover, it was found that the coexistence of both activating ${ }^{\mathrm{MUT}} E G F R$ and ${ }^{\mathrm{MUT}} K R A S$ was not necessarily a negative predictor for EGFR-TKI therapy [23]. With these evidences in mind, all patients with p.T790M $E G F R$ should receive third generation EGFR-TKI, even in the presence of ${ }^{\mathrm{MUT}} K R A S$. Theoretically, it is possible that ${ }^{\mathrm{MUT}} K R A S$ identify a less responsive subgroup of patients but this hypothesis should be validated by monitoring patients prospectically during secondline therapy. Beside ${ }^{\text {p.T790M }} E G F R$ and ${ }^{\mathrm{MUT}} K R A S$, other mechanisms of acquired resistance not evaluated in our study have been described in tumor re-biopsies after EGFR-TKI progression, including actionable mutations of MET [7], HER2 [8], PIK3CA [9] or transformation into small cell histology (3\%) [11].

In conclusion, despite the small number of patients involved, the retrospective analysis and the low rate of re-biopsies, our results confirm the importance of cftDNA analysis for the monitoring of secondary mutations associated with EGFR-TKI resistance in NSCLC and underline the role of a highly sensitive approach, i.e., ddPCR, for the detection of low-level mutations. The clinical relevance of these findings, expecially for what concerns ${ }^{\mathrm{MUT}} K R A S$, needs to be evaluated prospectively. These observations open new perspectives in the molecular mechanisms of acquired resistance, indicating a possible role of ${ }^{\mathrm{MUT}} K R A S$ in tumor escape from pharmacologic treatment. The effect of ${ }^{\mathrm{MUT}} K R A S$ in NSCLC with activating ${ }^{\mathrm{MUT}} E G F R$ needs to be further elucidated at the molecular level and encourages the development of inhibitors ${ }^{\mathrm{MUT}} K R A S$ for optimal treatment of patients.

\section{MATERIALS AND METHODS}

\section{Study population}

A total of 33 NSCLC patients with activating ${ }^{\mathrm{MUT}} E G F R$ (exon 19 deletion [ $\left.{ }^{\mathrm{ex} 19 \mathrm{del}} E G F R\right]$, exon 21 c.2573T $>\mathrm{G}$ $\left[{ }^{\mathrm{p} . \mathrm{L} 858 \mathrm{R}} E G F R\right]$ or exon 19 c.2240T $\left.>\mathrm{C}\left[{ }^{\mathrm{p} . \mathrm{L} 747 \mathrm{P}} E G F R\right]\right)$, receiving EGFR-TKI (gefitinib or erlotinib) as per approved indication were included in this study. The analysis of EGFR mutations in primary tumors was performed by standard diagnostic procedures in use in each centre participating to this study (i.e., EGFR TKI response ${ }^{\circledR}$, Diatech, Jesi, Italy; Therascreen $^{\circledR}$, Qiagen, Valencia, CA, USA). ${ }^{\text {MUT }} K R A S$ were not examined at the time of diagnosis

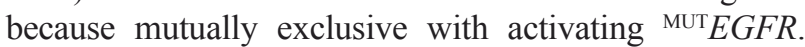
Plasma and/or re-biopsy samples were taken at the time of disease progression. The analysis of ${ }^{\mathrm{MUT}} K R A S$ mutations and $E G F R$ c. $2369 \mathrm{C}>\mathrm{T}\left({ }^{\mathrm{p} . \mathrm{T} 790 \mathrm{M}} E G F R\right)$ in plasma was not part of standard clinical management and the study was 
submitted and approved by the Ethics Committee of Pisa University Hospital and conducted in accordance to the principles of the Declaration of Helsinki; all patients gave their signed informed consent before blood collection and cftDNA analysis.

\section{Plasma collection and cftDNA extraction}

Six $\mathrm{ml}$ of blood were collected in EDTA and centrifuged at $4^{\circ} \mathrm{C}$ for $10 \mathrm{~min}$ at $3000 \mathrm{rpm}$ within two hours after blood drawing. Plasma samples were stored at $-80^{\circ} \mathrm{C}$ until analysis. cftDNA was extracted using a QIAmp Circulating nucleic acid Kit (Qiagen ${ }^{\circledR}$, Valencia, CA, USA) from 1 to $3 \mathrm{ml}$ of plasma following the manufacturer's protocol and the DNA was eluted in $100 \mu \mathrm{l}$ of buffer.

\section{Analysis of cftDNA}

The investigational part of this study included the assessment of codons 12, 13 (p.G13D) and $61{ }^{\text {MUT }} K R A S$ and ${ }^{\mathrm{MUT}} N R A S,{ }^{\mathrm{p} \cdot \mathrm{T} 790 \mathrm{M}} E G F R,{ }^{\mathrm{V} 600 \mathrm{E}} B R A F$ in cftDNA. Other mutations potentially associated with EGFR-TKI resistance were not examined because of the limited amount of cftDNA available. The analysis of cftDNA was performed by digital droplet PCR (ddPCR, BioRad ${ }^{\circledR}$, Hercules, CA, USA) and ddPCR Mutation Assay $\left(\right.$ BioRad $\left.^{\circledR}\right)$. The analytic procedure was unable to discriminate the nature of the MUT KRAS because the analysis was performed with a ddPCR KRAS Multiplex assay.

PCR reactions were assembled into individual wells of a single-use injection molded cartridge, according to the following protocol: $20 \mathrm{ng}$ of template DNA (4 $\mu \mathrm{l})$, $1 \mu \mathrm{l}$ of $20 \mathrm{X}$ target primer/probe assay (FAM), $1 \mu \mathrm{l}$ of $20 \mathrm{X}$ wild type primer/probe assay (HEX), $10 \mu \mathrm{l}$ of $2 \mathrm{X}$ ddPCR Super Mix and $4 \mu \mathrm{l}$ of DNAse/RNAse-free water up to a total volume of $20 \mu \mathrm{l}$. Droplet generation oil $(70 \mu \mathrm{l})$ was then loaded and the cartridge was placed into the droplet generator. Using vacuum, sample and oil were mixed, generating mono-disperse droplets. Thereafter, $40 \mu \mathrm{l}$ of packed droplets were transferred into a 96-well PCR plate for thermal cycling amplification. The protocol was standardized for all mutations to the following conditions: $95^{\circ} \mathrm{C} \times 10 \mathrm{~min}, 94^{\circ} \mathrm{C} \times 30 \mathrm{~s}$ and $55^{\circ} \mathrm{C} \times 60 \mathrm{~s}(35$ cycles $)$, $98^{\circ} \mathrm{C} \times 10 \mathrm{~min}$, and $4^{\circ} \mathrm{C}$ hold. The droplet reader $\left(\operatorname{BioRad}^{\circledR}\right)$ was used for fluorescence signal quantification. The concordance between ${ }^{\mathrm{MUT}} K R A S$ and ${ }^{\mathrm{p} \cdot{ }^{\mathrm{T} 790 \mathrm{M}} E G F R \text { was }}$ assessed on pairwise cftDNA and tissue DNA of 8 patients who underwent re-biopsy for diagnostic purposes. DNA was extracted from formalin-fixed paraffin-embedded biopsies using the QIAmp DNA Mini Kit (Qiagen ${ }^{\circledR}$ ) and analyzed using conventional diagnostics as reported above. As a positive control for ${ }^{\mathrm{MUT}} K R A S$, the cftDNA from 30 patients with known ${ }^{\mathrm{MUT}} K R A S$ pancreatic cancer was used, while the DNA extracted from plasma of 43 healthy blood donors was employed as negative control for ${ }^{\mathrm{MUT}} K R A S$ and ${ }^{\mathrm{p} . \mathrm{T} 790 \mathrm{M}} E G F R$.

\section{Data analysis}

TTP and OS were calculated following standard procedures and survival curves were generated by the SPSS statistical software (version 16).

\section{Financial support}

This study was supported in part by grants from the Italian Association for Cancer Research (AIRC, Italy), MIUR and ITT (Italy) and Fondazione Berlucchi (2014) to RD; AIRC (grant \#12182), CamPac FP7 (grant \#602783) and FIMP-Ministero Salute (CUP_J33G13000210001) to AS.

\section{REFERENCES}

1. Mok TS, Wu YL, Thongprasert S, Yang CH, Chu DT, Saijo N, Sunpaweravong $\mathrm{P}$, Han B, Margono B, Ichinose Y, Nishiwaki Y, Ohe Y, Yang JJ, et al. Gefitinib or carboplatinpaclitaxel in pulmonary adenocarcinoma. N Engl J Med. 2009; 361:947-957.

2. Rosell R, Carcereny E, Gervais R, Vergnenegre A, Massuti B, Felip E, Palmero R, Garcia-Gomez R, Pallares C, Sanchez JM, Porta R, Cobo M, Garrido P, et al. Erlotinib versus standard chemotherapy as first-line treatment for European patients with advanced EGFR mutation-positive non-small-cell lung cancer (EURTAC): a multicentre, open-label, randomised phase 3 trial. Lancet Oncol. 2012; 13:239-246.

3. Sequist LV, Yang JC, Yamamoto N, O’Byrne K, Hirsh V, Mok T, Geater SL, Orlov S, Tsai CM, Boyer M, Su WC, Bennouna J, Kato T, et al. Phase III study of afatinib or cisplatin plus pemetrexed in patients with metastatic lung adenocarcinoma with EGFR mutations. J Clin Oncol. 2013; 31:3327-3334.

4. Sequist LV, Waltman BA, Dias-Santagata D, Digumarthy S, Turke AB, Fidias P, Bergethon K, Shaw AT, Gettinger S, Cosper AK, Akhavanfard S, Heist RS, Temel J, et al. Genotypic and histological evolution of lung cancers acquiring resistance to EGFR inhibitors. Sci Transl Med. 2011; 3:75ra26.

5. Gainor JF, Shaw AT. Emerging paradigms in the development of resistance to tyrosine kinase inhibitors in lung cancer. $\mathrm{J}$ Clin Oncol. 2013; 31:3987-3996.

6. Shih JY, Gow CH, Yang PC. EGFR mutation conferring primary resistance to gefitinib in non-small-cell lung cancer. N Engl J Med. 2005; 353:207-208.

7. Bean J, Brennan C, Shih JY, Riely G, Viale A, Wang L, Chitale D, Motoi N, Szoke J, Broderick S, Balak M, Chang WC, Yu CJ, et al. MET amplification occurs with or without T790M mutations in EGFR mutant lung tumors with acquired resistance to gefitinib or erlotinib. Proc Natl Acad Sci U S A. 2007; 104:20932-20937.

8. Takezawa K, Pirazzoli V, Arcila ME, Nebhan CA, Song X, de Stanchina E, Ohashi K, Janjigian YY, Spitzler PJ, Melnick MA, Riely GJ, Kris MG, Miller VA, et al. HER2 
amplification: a potential mechanism of acquired resistance to EGFR inhibition in EGFR-mutant lung cancers that lack the second-site EGFRT790M mutation. Cancer Discov. 2012; 2:922-933.

9. Ludovini V, Bianconi F, Pistola L, Chiari R, Minotti V, Colella R, Giuffrida D, Tofanetti FR, Siggillino A, Flacco A, Baldelli E, Iacono D, Mameli MG, et al. Phosphoinositide-3-kinase catalytic alpha and KRAS mutations are important predictors of resistance to therapy with epidermal growth factor receptor tyrosine kinase inhibitors in patients with advanced non-small cell lung cancer. J Thorac Oncol. 2011; 6:707-715.

10. Ohashi K, Sequist LV, Arcila ME, Moran T, Chmielecki J, Lin YL, Pan Y, Wang L, de Stanchina E, Shien K, Aoe K, Toyooka S, Kiura K, et al. Lung cancers with acquired resistance to EGFR inhibitors occasionally harbor BRAF gene mutations but lack mutations in KRAS, NRAS, or MEK1. Proc Natl Acad Sci U S A. 2012; 109:E2127-2133.

11. Yu HA, Arcila ME, Rekhtman N, Sima CS, Zakowski MF, Pao W, Kris MG, Miller VA, Ladanyi M, Riely GJ. Analysis of tumor specimens at the time of acquired resistance to EGFR-TKI therapy in 155 patients with EGFR-mutant lung cancers. Clin Cancer Res. 2013; 19:2240-2247.

12. Ding L, Getz G, Wheeler DA, Mardis ER, McLellan MD, Cibulskis K, Sougnez C, Greulich H, Muzny DM, Morgan MB, Fulton L, Fulton RS, Zhang Q, et al. Somatic mutations affect key pathways in lung adenocarcinoma. Nature. 2008; 455:1069-1075.

13. Bosc C, Ferretti GR, Cadranel J, Audigier-Valette C, Besse B, Barlesi F, Decroisette C, Lantuejoul S, Arbib F, MoroSibilot D. Rebiopsy during disease progression in patients treated by TKI for oncogene-addicted NSCLC. Target Oncol. 2015; 10:247-253.

14. Del Re M, Vasile E, Falcone A, Danesi R, Petrini I. Molecular analysis of cell-free circulating DNA for the diagnosis of somatic mutations associated with resistance to tyrosine kinase inhibitors in non-small-cell lung cancer. Expert Rev Mol Diagn. 2014; 14:453-468.

15. Riely GJ, Ladanyi M. KRAS mutations: an old oncogene becomes a new predictive biomarker. J Mol Diagn. 2008; 10:493-495.

16. Godin-Heymann N, Bryant I, Rivera MN, Ulkus L, Bell DW, Riese DJ, 2nd, Settleman J, Haber DA. Oncogenic activity of epidermal growth factor receptor kinase mutant alleles is enhanced by the T790M drug resistance mutation. Cancer Res. 2007; 67:7319-7326.

17. Yun $\mathrm{CH}$, Mengwasser KE, Toms AV, Woo MS, Greulich H, Wong KK, Meyerson M, Eck MJ. The T790M mutation in EGFR kinase causes drug resistance by increasing the affinity for ATP. Proc Natl Acad Sci U S A. 2008; 105:2070-2075.

18. Oxnard GR, Paweletz CP, Kuang Y, Mach SL, O'Connell A, Messineo MM, Luke JJ, Butaney M, Kirschmeier P, Jackman DM, Janne PA. Noninvasive detection of response and resistance in EGFR-mutant lung cancer using quantitative next-generation genotyping of cell-free plasma DNA. Clin Cancer Res. 2014; 20:1698-1705.

19. Sorensen BS, Wu L, Wei W, Tsai J, Weber B, Nexo E, Meldgaard P. Monitoring of epidermal growth factor receptor tyrosine kinase inhibitor-sensitizing and resistance mutations in the plasma DNA of patients with advanced non-small cell lung cancer during treatment with erlotinib. Cancer. 2014; 120:3896-3901.

20. Taniguchi K, Uchida J, Nishino K, Kumagai T, Okuyama T, Okami J, Higashiyama M, Kodama K, Imamura F, Kato K. Quantitative detection of EGFR mutations in circulating tumor DNA derived from lung adenocarcinomas. Clin Cancer Res. 2011; 17:7808-7815.

21. Janne PA, Yang JC, Kim DW, Planchard D, Ohe Y, Ramalingam SS, Ahn MJ, Kim SW, Su WC, Horn L, Haggstrom D, Felip E, Kim JH, et al. AZD9291 in EGFR inhibitor-resistant non-small-cell lung cancer. N Engl J Med. 2015; 372:1689-1699.

22. Sequist LV, Soria JC, Goldman JW, Wakelee HA, Gadgeel SM, Varga A, Papadimitrakopoulou V, Solomon BJ, Oxnard GR, Dziadziuszko R, Aisner DL, Doebele RC, Galasso C, et al. Rociletinib in EGFR-mutated non-smallcell lung cancer. N Engl J Med. 2015; 372:1700-1709.

23. Benesova L, Minarik M, Jancarikova D, Belsanova B, Pesek M. Multiplicity of EGFR and KRAS mutations in non-small cell lung cancer (NSCLC) patients treated with tyrosine kinase inhibitors. Anticancer Res. 2010; 30:1667-1671.

24. Choughule A, Sharma R, Trivedi V, Thavamani A, Noronha V, Joshi A, Desai S, Chandrani P, Sundaram P, Utture S, Jambhekar N, Gupta S, Aich J, et al. Coexistence of KRAS mutation with mutant but not wild-type EGFR predicts response to tyrosine-kinase inhibitors in human lung cancer. Br J Cancer. 2014; 111:2203-2204.

25. Riely GJ, Kris MG, Rosenbaum D, Marks J, Li A, Chitale DA, Nafa K, Riedel ER, Hsu M, Pao W, Miller VA, Ladanyi M. Frequency and distinctive spectrum of KRAS mutations in never smokers with lung adenocarcinoma. Clin Cancer Res. 2008; 14:5731-5734.

26. Martin P, Leighl NB, Tsao MS, Shepherd FA. KRAS mutations as prognostic and predictive markers in nonsmall cell lung cancer. J Thorac Oncol. 2013; 8:530-542.

27. Vakiani E, Solit DB. KRAS, BRAF: drug targets and predictive biomarkers. J Pathol. 2011; 223:219-229.

28. Kasper S, Breitenbuecher F, Reis H, Brandau S, Worm K, Kohler J, Paul A, Trarbach T, Schmid KW, Schuler M. Oncogenic RAS simultaneously protects against antiEGFR antibody-dependent cellular cytotoxicity and EGFR signaling blockade. Oncogene. 2013; 32:2873-2881.

29. Mao C, Qiu LX, Liao RY, Du FB, Ding H, Yang WC, Li J, Chen Q. KRAS mutations and resistance to EGFR-TKIs treatment in patients with non-small cell lung cancer: a metaanalysis of 22 studies. Lung Cancer. 2010; 69:272-278.

30. Massarelli E, Varella-Garcia M, Tang X, Xavier AC, Ozburn NC, Liu DD, Bekele BN, Herbst RS, Wistuba, II. 
KRAS mutation is an important predictor of resistance to therapy with epidermal growth factor receptor tyrosine kinase inhibitors in non-small-cell lung cancer. Clin Cancer Res. 2007; 13:2890-2896.

31. Bivona T, Giannikopoulos P, Costa C. Integrated genomic analysis by whole exome and transcriptome sequencing of tumor samples from EGFR-mutant non-small-cell lung cancer (NSCLC) patients with acquired resistance to erlotinib. J Thorac Oncol. 2013; 8:MO21.05.

32. Diaz LA, Jr, Williams RT, Wu J, Kinde I, Hecht JR, Berlin J, Allen B, Bozic I, Reiter JG, Nowak MA, Kinzler KW, Oliner KS, et al. The molecular evolution of acquired resistance to targeted EGFR blockade in colorectal cancers. Nature. 2012; 486:537-540.

33. Misale S, Yaeger R, Hobor S, Scala E, Janakiraman M, Liska D, Valtorta E, Schiavo R, Buscarino M, Siravegna G, Bencardino K, Cercek A, Chen CT, et al. Emergence of KRAS mutations and acquired resistance to anti-EGFR therapy in colorectal cancer. Nature. 2012; 486:532-536.
34. Baker NM, Der CJ. Cancer: Drug for an 'undruggable' protein. Nature. 2013; 497:577-578.

35. Cox AD, Fesik SW, Kimmelman AC, Luo J, Der CJ. Drugging the undruggable RAS: Mission possible? Nat Rev Drug Discov. 2014; 13:828-851.

36. Tricker EM, Xu C, Uddin S, Capelletti M, Ercan D, Ogino A, Pratilas CA, Rosen N, Gray NS, Wong KK, Janne PA. Combined EGFR/MEK Inhibition Prevents the Emergence of Resistance in EGFR-Mutant Lung Cancer. Cancer Discov. 2015; 5:960-971. 